\title{
Carvedilol in hypertension treatment
}

\author{
Panagiotis C Stafylas \\ Pantelis A Sarafidis \\ Ist Department of Medicine, AHEPA \\ University Hospital, Aristotle \\ University, Thessaloniki, Greece
}

\begin{abstract}
Although $\beta$-blockers have been previously shown to effectively reduce blood pressure (BP) and have been used for hypertension treatment for over 40 years, their effect on cardiovascular morbidity and mortality in hypertensive patients remains controversial and its use in uncomplicated hypertension is currently under debate. However, data on the above field derive mainly from studies which were conducted with older agents, such as atenolol and metoprolol, while considerable pharamacokinetic and pharmacodynamic heterogeneity is present within the class of $\beta$-blockers. Carvedilol, a vasodilating non-cardioselective $\beta$-blocker, is a compound that seems to give the opportunity to the clinician to use a cardioprotective agent without the concerning hemodynamic and metabolic actions of traditional $\beta$-blocker therapy. In contrast with conventional $\beta$-blockers, carvedilol maintains cardiac output, has a less extended effect on heart rate and reduces BP by decreasing vascular resistance. Further, several studies has shown that carvedilol has a beneficial or at least neutral effect on metabolic parameters, such as glycemic control, insulin sensitivity, and lipid metabolism, suggesting that they could be used in subjects with the metabolic syndrome or diabetes without negative consequences. This article summarizes the distinct pharmacologic, hemodynamic, and metabolic properties of carvedilol in relation to conventional $\beta$-blockers, attempting to examine the potential use of this agent for hypertension treatment.
\end{abstract}

Keywords: carvedilol, $\beta$-blockers, hypertension treatment

\section{Introduction}

Hypertension represents the most common cardiovascular risk factor. Its prevalence is continuously rising, affecting more than $25 \%$ of the adult population in developed societies (Wolf-Maier et al 2004; Sarafidis et al 2004; Sarafidis and Bakris 2008). On the other hand, several previous studies have clearly shown longitudinal associations between hypertension and coronary artery disease, myocardial infarction, stroke, congestive heart failure, and peripheral vascular disease (MacMahon et al 1990; Stamler et al 1993) and lowering blood pressure (BP) significantly reduces the cardiovascular morbidity and mortality (Collins et al 1990; MacMahon et al 1997). However, control rates of hypertension is currently inappropriate and the majority of the hypertensive patients will require two or more antihypertensive agents to reach target BP goals (Chobanian et al 2003; ESH-ESC Guidelines Committee 2003; Mancia et al 2007).

Beta-blockers have been used for more than 40 years to treat hypertension (Sarafidis and Bakris 2006b). Data from clinical trials that used these agents to manage BP have demonstrated reductions in cardiovascular mortality and this has resulted in recommendations of $\beta$-blockers as first- or second-line antihypertensive agents in the most recent guidelines of the European Society of Hypertension/European Society of Cardiology (Mancia et al 2007) and the Joint National Committee (JNC 7) on the Prevention, Detection and Treatment of High Blood Pressure (Chobanian et al 2003). All of the $\beta$-blocker compounds now available for use have been approved for the treatment of hypertension 
(Opie and Yusuf 2005). Despite the above and the wide use of $\beta$-blockers for the management of hypertension, their use in patients with uncomplicated hypertension has become increasingly controversial over the past few years (Sarafidis and Bakris 2006c; Black and Sica 2007). This was in part due to the results of recent meta-analyses showing no difference between atenolol and placebo in risk reduction for mortality, myocardial infarction, or stroke (Carlberg et al 2004) and an increased risk of mortality and stroke with atenolol or propranolol in comparison to other antihypertensive drug classes, including diuretics, angiotensin-converting enzyme (ACE) inhibitors, angiotensin receptor blockers (ARBs), and calciumchannel blockers (CCBs) (Carlberg et al 2004; Lindholm et al 2005). The recently updated National Institute for Health and Clinical Excellence guidelines in Great Britain reflected this concern, having changed the indication for $\beta$-blockers from use as first-line agents for hypertension treatment to consideration as a fourth-line add-on therapy in patients requiring multiple drugs (Williams et al 2004; National Collaborating Centre for Chronic Conditions 2006). In the most recent guidelines, the European Society of Hypertension / European Society of Cardiology (Mancia et al 2007) recommend that $\beta$-blockers should not be preferred in hypertensives with multiple metabolic risk factors including metabolic syndrome, abdominal obesity, high normal or impaired fasting glucose, and impaired glucose tolerance, conditions that make the risk of incident diabetes higher.

Although the above data on $\beta$-blockers and CVD risk reduction cannot be overlooked, one must always bear in mind that most of the studies on the field included "traditional" agents (such as propranolol and atenolol). This notion is of great importance, since, although a class effect is possible for certain facets of $\beta$-blocker action, many effects of the various $\beta$-blockers differ greatly between the various compounds, according to the individual physicochemical and pharmacological properties of each of them (Williams et al 2004). Several head-to-head studies have convincingly shown that non-selective agents, such as atenolol, have a negative effect on myocardial contractility, vascular resistance (Man et al 1988), and carbohydrate and lipid metabolism (Sarafidis and Bakris 2007), while newer agents with vasodilating properties, such as carvedilol and nebivolol, have a hemodynamic and metabolic profile that is much better than that of older compounds (Sarafidis and Bakris 2006b; Weiss 2006; Sica 2007). The present review summarizes the current data on the pharmacologic, hemodynamic, and metabolic properties of carvedilol in comparison with conventional $\beta$-blocking compounds, in an attempt to examine whether this particular agent could be still useful in the treatment of hypertension.

\section{Pharmacologic properties of $\beta$-blockers}

First generation $\beta$-blockers, such as propranolol, block both $\beta_{1}$ - and $\beta_{2}$-receptors. Through $\beta_{1}$-receptor blocking these compounds induce the well known inhibitory effects on the function of the sinus and atrioventricular nodes and on myocardial contraction (negative chronotropic, dromotropic, and inotropic effect). By blocking the $\beta_{2}$-receptors, they cause contraction of smooth muscle with a risk of bronchospasm in predisposed individuals (Kaplan 2005b; Opie and Yusuf 2005). Second-generation agents, such as atenolol, metoprolol, and others, have relative low selectivity when given in low doses for the $\beta_{1}$-receptors and they are preferable in patients with chronic lung disease or in chronic smokers. Finally, third-generation agents such as labetalol and carvedilol have additional vasodilatory properties due to $\alpha$-adrenergic blockade capacity (Table 1) (Frishman 1998; Sica 2007). Even in small doses, $\beta$-blockers begin to lower BP within a few hours (Kaplan 2005b). The plasma half-live of the various $\beta$-blockers range from just 9 minutes for esmolol to 24 hours for nadolol and penbutolol (median half-live of the class about 6 hours), but the effective half-life is longer mainly because of the active metabolites. Longer-acting compounds such as nadolol and extended-release formulations such as slow-release propranolol or extended-release metoprolol increase the probability of medication adherence and should be preferred for treatment of hypertension (Opie and Yusuf 2005).

Carvedilol is a third-generation, vasodilating noncardioselective $\beta$-blocker which lacks intrinsic sympathomimetic activity (ISA). In addition to its $\beta$-blocking effects, it has blocking effects at vascular $\alpha_{1}$-receptors, antioxidant, and calcium antagonist properties (Opie and Yusuf 2005). Experimental models demonstrate that carvedilol blocks $\alpha_{1}-, \beta_{1}-$, and $\beta_{2}$-adrenergic receptors (McTavish et al 1993) without exhibiting high levels of inverse agonist activity. The lack of inverse agonist activity and ISA reduces the side-effects and makes the compound better tolerated than the older $\beta$-blockers (Yoshikawa et al 1996).

Carvedilol is rapidly absorbed after an oral dose, reaching peak plasma drug concentrations within 1 to 2 hours. Absorption is delayed an additional 1 to 2 hours when the drug is administered with food (Morgan 1994). The plasma half-life of carvedilol ranges from 7 to 10 hours in most subjects; thus, the drug requires twice-daily dosing. In plasma, $98 \%$ of the drug is bound to plasma proteins, predominantly to albumin 
Table I Pharmacologic properties of $\beta$-blockers

\begin{tabular}{|c|c|c|c|c|c|c|c|}
\hline Generic name & $\begin{array}{l}\beta_{1-} \\
\text { selective }\end{array}$ & $\begin{array}{l}\alpha- \\
\text { blocker }\end{array}$ & ISA & $\begin{array}{l}\text { Lipid } \\
\text { solubility }\end{array}$ & $\begin{array}{l}\text { Loss by liver or } \\
\text { kidney }\end{array}$ & $\begin{array}{l}\text { Plasma } \\
\text { Half-life (h) }\end{array}$ & $\begin{array}{l}\text { Plasma protein } \\
\text { binding (\%) }\end{array}$ \\
\hline \multicolumn{8}{|c|}{ Noncardioselective } \\
\hline Propranolol & - & - & - & +++ & Liver & $1-6$ & 90 \\
\hline Carteolol & - & - & + & $0 /+$ & Kidney & $5-6$ & $20-30$ \\
\hline Nadolol & - & - & - & 0 & Kidney & $20-24$ & 30 \\
\hline Penbutolol & - & - & + & +++ & Liver & $20-25$ & 98 \\
\hline Sotalol & - & - & - & 0 & Kidney & $7-18$ & 5 \\
\hline Timolol & - & - & - & + & Liver, kidney & $4-5$ & 60 \\
\hline \multicolumn{8}{|l|}{ Cardioselective } \\
\hline Acebutolol & + & - & ++ & 0 & Liver, kidney & $8-13$ & 15 \\
\hline Atenolol & + & - & - & 0 & Kidney & $6-7$ & 10 \\
\hline Betaxolol & + & - & - & ++ & Liver then kidney & $14-22$ & 50 \\
\hline Bisoprolol & + & - & - & + & Liver, kidney & $9-12$ & 30 \\
\hline Metoprolol & + & - & - & + & Liver & $3-7$ & 12 \\
\hline \multicolumn{8}{|c|}{ Vasodilatory $\beta$-blockers } \\
\hline \multicolumn{8}{|l|}{ nonselective } \\
\hline Labetalol & - & + & - & +++ & Liver, some kidney & $6-8$ & 90 \\
\hline Pindolol & - & + & +++ & + & Liver, kidney & 4 & 55 \\
\hline Carvedilol & - & + & - & + & Liver & 6 & 95 \\
\hline \multicolumn{8}{|c|}{$\begin{array}{l}\text { Vasodilatory } \beta \text {-blockers, } \\
\text { cardioselective }\end{array}$} \\
\hline Celiprolol & + & + & + & $0 /+$ & Kidney, then liver & $6-8$ & - \\
\hline Nebivolol & + & - & - & + & Liver & $10-30^{\mathrm{a}}$ & 98 \\
\hline
\end{tabular}

Modified from Opie and Yusuf (2005)

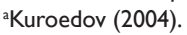

Abbreviation: ISA, intrinsic sympathomimetic activity.

(Morgan 1994). Carvedilol is almost exclusively metabolized by the liver and its metabolism is affected by genetic polymorphism of cytochrome P-450 2D6 activity. Drugs that inhibit cytochrome P-450 2D6 activity, such as quinidine, paroxetine, fluoxetine, and propafenone, may also increase plasma carvedilol concentrations. Thus, patients taking these drugs may be at particularly high risk of hypotension due to excessive $\alpha$-adrenoreceptor blockade. Clearance of carvedilol is delayed in patients over 65 years of age. On average, their plasma carvedilol concentrations are 50\% higher than in younger patients (Frishman 1998). The pharmacokinetics of carvedilol are significantly altered in patients with liver disease but not so in the presence of renal failure (Neugebauer et al 1992; Kramer et al 1992; Frishman 1998). Less than 2\% of the parent drug recovers in the urine (Frishman 1998). Some of the metabolites of carvedilol have $\beta$-adrenoreceptorantagonist activity, and one 4-hydroxyphenyl metabolite is approximately 13 times as potent as carvedilol in this regard. Approximately $60 \%$ of these metabolites are secreted with bile and excreted with the faeces (Frishman 1998).

\section{Hemodynamic effects of carvedilol}

Essential hypertension is a disease with complex aetiology and various factors are implicated in its pathogenesis.
In terms of the circulation, elevations in BP can be the result of either an increase in cardiac output or a rise in peripheral vascular resistance (Kaplan 2005a). The development of the essential hypertension is usually slow and gradual and regardless of the triggering mechanism, eventually increased peripheral vascular resistance becomes the main hemodynamic fault (Lever and Harrap 1992).

Most antihypertensive agents act through a decrease in vascular resistance while sparing cardiac output, but traditional $\beta$-blockers are an exception to this rule. The most common ways by which non-vasodilating $\beta$-blockers reduce BP include a decrease in cardiac output, sympathetic outflow, and, probably, renin release while systemic vascular resistance remains unchanged or even increases (Messerli and Grossman 2004; Black and Sica 2007). In contrast, carvedilol seems to lower BP by decreasing peripheral vascular resistance, without affecting cardiac output; due to the $\alpha_{1}$-adrenergic blocking effect, which accounts for its vasodilatory effects, the hemodynamic effect of carvedilol is similar to those of ACE inhibitors and CCBs (Frishman 1998) and it can be expected to have a more consistent BP-lowering effect than do traditional $\beta$-blockers, such as atenolol or metoprolol (Messerli and Grossman 2004).

Hypertension is associated with the development of left ventricular hypertrophy $(\mathrm{LVH})$ and LVH is strongly related to 
subsequent cardiovascular morbidity and mortality (Messerli et al 1993; Benjamin and Levy 1999). All antihypertensive agents have been shown to cause regression of LVH, but $\beta$-blockers seem to be less effective to this end (Fleischmann and Schmieder 2002; Verdecchia et al 2004; Gosse 2005). Schulman et al (1990) reported that atenolol failed to reduce $\mathrm{LVH}$ in the elderly when compared with verapamil. In the Losartan Intervention for End-Point Reduction in Hypertension (LIFE) study (Dahlof et al 2002), losartan was more efficacious than atenolol in LVH reduction. Although Galzerano et al (2005) reported a superior left ventricular mass regression with telmisartan versus carvedilol, the latter may have a more beneficial effect on LVH compared with the conventional $\beta$-blockers, due to its vasodilating properties (Messerli and Grossman 2004); however no double-blind study comparing carvedilol with traditional $\beta$-blockers in patients with LVH is currently available.

\section{Effects of carvedilol on insulin sensitivity and glycemic control}

For more than 20 years one of the hottest research topics in the field of hypertension therapeutics was the actions of the various agents used for hypertension treatment on parameters related to carbohydrate metabolism (Sarafidis and Bakris 2006a). A considerable number of clinical studies have examined the effects of the various antihypertensive classes on insulin sensitivity (IS), glycemic control, and incidence of diabetes mellitus. The broad conclusion is that thiazide diuretics and $\beta$-blockers deteriorate IS and thus increase the propensity of hypertensive patients to new-onset diabetes, whereas ACEinhibitors, CCBs and ARBs have rather neutral or beneficial effects on these parameters (Sarafidis and Bakris 2006b, d).

However, accumulating evidence suggests that with regard to $\beta$-blockers an important exception apply to the above general "rule"; newer, vasodilating, agents seem to have a much different metabolic profile than older ones (Sarafidis and Bakris 2006d). Previous studies using the euglycemic hyperinsulinemic clamp technique have shown that treatment of hypertensive patients with conventional $\beta$-blockers, either nonselective, like propranolol (Lithell et al 1992), or $\beta 1$-selective, like atenolol (Pollare et al 1989a; Pollare et al 1989b) or metoprolol (Pollare et al 1989b), decreases IS by about 15\%-35\%. In addition, in the LIFE study (Dahlof et al 2002), patients who received atenolol experienced a $25 \%$ greater risk of new-onset diabetes compared with those who received losartan.

In contrast, some studies suggest that newer $\beta$-blockers with vasodilating properties can have beneficial effects on parameters as glycemic control and insulin sensitivity (Haenni and Lithell 1994; Malminiemi 1995). Jacob et al have previously compared the effects of carvedilol and metoprolol in 72 hypertensive patients and observed a 14\% increase in IS estimated with the clamp with carvedilol afterwards, whereas metoprolol was associated with a reduction in this parameter (Haenni and Lithell 1994; Jacob et al 1996). In another study of the field, Giuglano et al investigated the effects of carvedilol and atenolol in 45 patients with both hypertension and type 2 diabetes. After 24 weeks of treatment, fasting plasma glucose and HbA1c were decreased and IS measured with the clamp was increased with carvedilol, whereas atenolol had the opposite results (Giugliano et al 1997). In the Carvedilol or Metoprolol European Trial (COMET) study (Poole-Wilson et al 2003), the risk for new-onset diabetes was $22 \%$ lower in patients receiving carvedilol than those receiving metoprolol. In addition, the Glycemic Effects in Diabetes Mellitus: Carvedilol-Metoprolol Comparison in Hypertensives (GEMINI) multi-center trial (Bakris et al 2004), that compared carvedilol with metoprolol treatment in 1235 subjects with hypertension and type 2 diabetes showed a significant decrease in the HOMA-IR index of about $9 \%$ with carvedilol. These findings clearly support a less detrimental effect of vasodilating compared with older $\beta$-blockers on glycemic control and insulin sensitivity and suggest that among the class of $\beta$-blockers, the former agents should be preferred in subjects with components of the metabolic syndrome, impaired glucose tolerance or type 2 diabetes.

\section{Effects of carvedilol on lipid metabolism}

Several studies have shown that $\beta$-blockers increase triglyceride levels and decrease high-density lipoprotein (HDL) levels (Kasiske et al 1995; Brook 2000; Maitland-van der Zee et al 2001). Cardioselective $\beta$-blockers with ISA have a lesser effect on triglycerides and HDL levels than non-cardioselective $\beta$-blockers without ISA ( Pollare et al 1989b; Roberts 1989; Kasiske et al 1995). In a review of 474 studies, Kasiske et al showed also that long-term treatment with $\beta$-blockers reduces the effect on HDL levels (Kasiske et al 1995).

In contrast to older $\beta$-blockers, carvedilol seems to have a neutral or beneficial effect on lipoprotein lipase activity and levels of triglycerides and HDL (Giugliano et al 1997; Bakris et al 2004). In 45 patients with non-insulin-dependent diabetes and hypertension who were treated for 24 weeks, patients receiving carvedilol had a more favorable effect compared with atenolol in lowering triglyceride levels, increasing HDL levels, and decreasing lipid peroxidation 
(Giugliano et al 1997). These beneficial effects of carvedilol on lipid levels is another important advantage of this agent in comparison to the conventional compounds.

\section{Hypertension-induced nephropathy}

Hypertension is a well-established risk factor for chronic kidney disease (Sarafidis et al 2007) and hypertensive renal disease is the second major cause of end-stage renal disease in the developed societies (US Renal Data System 2005). Microalbuminuria, which can be found in many hypertensive patients, is considered today a marker of abnormal vascular function and a risk factor of cardiovascular disease, while elevation of urine albumin excretion at levels of macroalbuminuria is considered as a typical sign of overt nephropathy and is directly associated with the rate of renal function decline (Sarafidis and Bakris 2006e). As hypertension-induced nephrosclerosis proceeds, renal blood flow and glomerular filtration rate decrease, and filtration fraction increases long before plasma creatinine level begins to rise. Non-vasodilating $\beta$-blockers further decrease renal blood flow and increase filtration fraction. In addition, although short-term therapy with $\beta$-blockers decreases microalbuminuria, long-term therapy fails to reduce microalbuminuria compared with ACE inhibitors or nondihydropyridine $\mathrm{CCB}$, despite equal antihypertensive efficacy (Hannedouche et al 1994) and there is general no evidence that conventional $\beta$-blockers possess renoprotective properties.

In contrast to traditional $\beta$-blockers, several trials have demonstrated a beneficial effect of carvedilol on kidney function including an increase in renal blood flow and a reduction in microalbuminuria (Dupont et al 1987; Dupont 1990; Marchi and Ciriello 1995; Agrawal et al 1996). In addition, in GEMINI trial (Bakris et al 2004), among patients with normal urine albumin excretion in baseline, fewer progressed to microalbuminuria in the carvedilol than in the metoprolol group (6.4\% vs $10.3 \%$ respectively). These findings support a possible beneficial effect of carvedilol on renal function and call for a prospective trial examining the effect of this drug on hard renal end-points (ie, incidence of end-stage renal disease) in patients with chronic kidney disease and proteinuria.

\section{Elderly patients}

The Swedish Trial in Old Patients with Hypertension (STOP-Hypertension) (Dahlof et al 1991) found a significant reduction in the incidence of stroke and cardiovascular mortality by $\beta$-blockade (atenolol, metoprolol, or pindolol usually combined with diuretics) but just a marginal reduction in the incidence of myocardial infarction. In the elderly, aging is accompanied by a progressive decrease in cardiovascular responsiveness to $\beta$-adrenergic stimulation and by an increase in plasma catecholamine levels, similar to the effects observed with pharmacologic $\beta$-blockade (Messerli and Grossman 2004). Fleg et al (1994) showed that the ageassociated decreases in maximal heart rate and left ventricular contractility with exercise are probably manifestations of a reduced $\beta$-adrenergic responsiveness and thus adding $\beta$-blockers may result in poor tolerability in elderly patients. The $\alpha$-blocking effect of carvedilol may counterbalance some of the negative chronotropic and inotropic effects associated with older $\beta$-blockers and may have a more favorable effect on cardiovascular function in the elderly, being better tolerated in the same time (Messerli and Grossman 2004).

\section{Concomitant diseases}

Use of $\beta$-blockers in patients with hypertension is specifically recommended in the presence of concomitant coronary disease, particularly after myocardial infarction, congestive heart failure, or tachyarrythmias (Chobanian et al 2003; Mancia et al 2007). If a $\beta$-blocker is chosen, the agents that are more cardioselective offer the likelihood of fewer perturbations of lipid and carbohydrate metabolism and greater adherence of patients to therapy; only one dose a day is needed, and side effects are probably minimized (Kaplan 2005b).

When $\beta$-blockers are used for the treatment of hypertension, the blockade of $\beta$-adrenergic receptors may worsen certain concomitant diseases, such as peripheral vascular disease, chronic obstructive pulmonary disease, diabetes, depression and sexual dysfunction (Kaplan 2005b). Although none of these comorbid conditions is an absolute contraindication to pharmacologic $\beta$-blockade, they are prone to decrease the patient's tolerability for $\beta$-blockers (Messerli and Grossman 2004). The most common side-effect of $\beta$-blockade is fatigue, probably a consequence of decreased cardiac output and peripheral and cerebral blood flow (Kaplan 2005b). Whereas negative effects of carvedilol on bronchospasm and depression are unlikely to be different from older $\beta$-blockers, the $\mathrm{a}_{1}$-blocking effects of carvedilol have been shown to be beneficial in patients with diabetes (Sarafidis and Bakris 2006b), as discussed above and peripheral vascular disease (Messerli and Grossman 2004).

Concerning sexual dysfunction Fogari et al (2001) compared the effect of carvedilol and valsartan on sexual activity in hypertensive men who were never treated for hypertension and without any previous sexual disfunction and they found that carvedilol induces a chronic worsening of sexual activity, 
whereas valsartan not only does not significantly worsen sexual activity but may even improve it; however, no doubleblind study comparing the effect of carvedilol and traditional $\beta$-blockers on sexual activity is currently available.

\section{Controlled-release carvedilol}

Recently, a controlled-release formulation of carvedilol (carvedilol CR) has been developed, allowing once-daily dosing and, thus, better adherence to medication (Osterberg and Blaschke 2005). Carvedilol CR is also indicated in patients with hypertension starting at a dose of $20 \mathrm{mg}$. A recently published study showed that carvedilol CR once daily were equivalent to carvedilol twice daily in bioavailability parameters (maximum plasma concentrations and trough drug concentration) in all doses likely to be used in hypertension (20, 40 , and $80 \mathrm{mg}$ ). The maximum concentration of carvedilol with the controlled-release formulation is reached approximately 3.5 hours later than what is seen with the immediate-release preparation (Tenero et al 2006) reducing the possibility of concentration-dependent side effects (Packer 2006).

In a recently published study, Weber et al (2006) have shown that once-daily administration of carvedilol CR for 6 weeks in doses ranging from 20 to $80 \mathrm{mg}$, alone or in combination with other agents, produced sustained diastolic and systolic BP and heart rate reduction compared with placebo and an important BP-lowering effect into the early morning hours. Another study in 122 hypertensive patients, Henderson et al (Henderson et al 2006) evaluated the side-effect profile of patients switching from carvedilol twice daily to carvedilol CR. Patients assigned to the lowest dosage of carvedilol (6.25 mg twice daily) for 22 days were switched to the comparable lowest dosage of carvedilol CR (20 mg once daily) for 8 days, and subjects assigned to the high target dosage of carvedilol ( $25 \mathrm{mg}$ twice daily) for 22 days were switched to the comparable high dosage of carvedilol CR ( $80 \mathrm{mg}$ once daily) for 8 days. Patients experienced fewer adverse events following the switch from the twice daily formulation to the $\mathrm{CR}$ formulation for either the lower and higher doses of carvedilol (Henderson et al 2006). Multicenter studies in patients with hypertension comparing the effect of carvedilol CR with atenolol and metoprolol on surrogate markers of disease are currently underway and are waited to expand our knowledge in the field.

\section{Conclusions}

During the past years, several studies and meta-analyses have demonstrated a beneficial effect of $\beta$-blockers compared with placebo on the surrogate end-point of BP but their effect on cardiovascular morbidity and mortality in patients with uncomplicated hypertension remains controversial (Messerli et al 1998). Based on two recent randomized trials (Dahlof et al 2002, 2005) and in a recently published meta-analysis (Lindholm et al 2005), demonstrating that $\beta$-blockers were less effective than the comparator drug at reducing major cardiovascular events, the British Hypertension Society (National Collaborating Centre for Chronic Conditions 2006) has recently updated the guidelines for the management of hypertension, recommending that in the absence of other compelling indications for $\beta$-blockade, $\beta$-blockers should not be a preferred initial treatment for hypertension. More recently, the European Society of Hypertension/European Society of Cardiology (Mancia et al 2007) recommend that $\beta$-blockers should not be preferred in hypertensives with multiple metabolic risk factors. These conclusions and recommendations mainly derive from studies that were conducted with older agents, such as atenolol and metoprolol, but it is well documented that there is considerable pharamacokinetic and pharmacodynamic heterogeneity among $\beta$-blockers. Carvedilol, a vasodilating noncardioselective $\beta$-blocker, represents an opportunity to use a cardioprotective agent without the concerning hemodynamic and metabolic responses associated with traditional $\beta$-blocker therapy. In contrast to classic $\beta$-blockers, carvedilol maintains cardiac output, has a lesser effect on heart rate, and decreases BP mainly by decreasing vascular resistance. Studies comparing carvedilol with conventional $\beta$-blocking agents showed that this compound has much better effects on glycemic control, insulin sensitivity, and lipid metabolism, suggesting that it could be used in subjects with metabolic syndrome or diabetes without the fear of deterioration of these parameters. Futher, the distinct hemodynamic and metabolic features of carvedilol could result in beneficial actions in concomitant diseases, such as renal disease, peripheral vascular disease and others. For a definite answer on the possible benefits of vasodilating over conventional $\beta$-blockers, studies not only on these surrogate parameters but also on hard cardiovascular outcomes are needed. With the available evidence however, it is possible that carvedilol could be a valuable tool in the clinicians' hand in the difficult task of hypertension management.

\section{References}

Agrawal B, Wolf K, Berger A, et al. 1996. Effect of antihypertensive treatment on qualitative estimates of microalbuminuria. J Hum Hypertens, 10:551-5.

Bakris GL, Fonseca V, Katholi RE, et al. 2004. Metabolic effects of carvedilol vs metoprolol in patients with type 2 diabetes mellitus and hypertension: a randomized controlled trial. JAMA, 292:2227-36.

Benjamin EJ, Levy D. 1999. Why is left ventricular hypertrophy so predictive of morbidity and mortality? Am J Med Sci, 317:168-75. 
Black HR, Sica DA. 2007. A modern perspective on beta-blocker use in hypertension: clinical trials and their influence on clinical practice. J Clin Hypertens (Greenwich), 9:10-18.

Brook RD. 2000. Mechanism of differential effects of antihypertensive agents on serum lipids. Curr Hypertens Rep, 2:370-7.

Carlberg B, Samuelsson O, Lindholm LH. 2004. Atenolol in hypertension: is it a wise choice? Lancet, 364:1684-9.

Chobanian AV, Bakris GL, Black HR, et al. 2003. The Seventh Report of the Joint National Committee on Prevention, Detection, Evaluation, and Treatment of High Blood Pressure: the JNC 7 report. JAMA, 289:2560-72.

Collins R, Peto R, MacMahon S, et al. 1990. Blood pressure, stroke, and coronary heart disease. Part 2, Short-term reductions in blood pressure: overview of randomised drug trials in their epidemiological context. Lancet, 335:827-38.

Dahlof B, Devereux RB, Kjeldsen SE, et al. 2002. Cardiovascular morbidity and mortality in the Losartan Intervention For Endpoint reduction in hypertension study (LIFE): a randomised trial against atenolol. Lancet, 359:995-1003.

Dahlof B, Lindholm LH, Hansson L, et al. 1991. Morbidity and mortality in the Swedish Trial in Old Patients with Hypertension (STOPHypertension). Lancet, 338:1281-5.

Dahlof B, Sever PS, Poulter NR, et al. 2005. Prevention of cardiovascular events with an antihypertensive regimen of amlodipine adding perindopril as required versus atenolol adding bendroflumethiazide as required, in the Anglo-Scandinavian Cardiac Outcomes Trial-Blood Pressure Lowering Arm (ASCOT-BPLA): a multicentre randomised controlled trial. Lancet, 366:895-906.

Dupont AG. 1990. Effects of carvedilol on renal function. Eur J Clin Pharmacol, 38 Suppl 2:S96-100.

Dupont AG, Van der NP, Taeymans Y, et al. 1987. Effect of carvedilol on ambulatory blood pressure, renal hemodynamics, and cardiac function in essential hypertension. J Cardiovasc Pharmacol, 10 Suppl 11 S130-S6.

ESH-ESC Guidelines Committee. 2003. 2003 European Society of Hypertension-European Society of Cardiology guidelines for the management of arterial hypertension. J Hypertens, 21:1011-53.

Fleg JL, Schulman S, O'Connor F, et al. 1994. Effects of acute beta-adrenergic receptor blockade on age-associated changes in cardiovascular performance during dynamic exercise. Circulation, 90:2333-41.

Fleischmann EH, Schmieder RE. 2002. Are all antihypertensive drug classes equal in reducing left ventricular hypertrophy? Curr Cardiol Rep, 4:474-8.

Fogari R, Zoppi A, Poletti L, et al. 2001. Sexual activity in hypertensive men treated with valsartan or carvedilol: a crossover study. $\mathrm{Am} \mathrm{J}$ Hypertens, 14:27-31.

Frishman WH. 1998. Carvedilol. N Engl J Med, 339:1759-65.

Galzerano D, Tammaro P, del VL, et al. 2005. Three-dimensional echocardiographic and magnetic resonance assessment of the effect of telmisartan compared with carvedilol on left ventricular mass a multicenter, randomized, longitudinal study. Am J Hypertens, 18:1563-9.

Giugliano D, Acampora R, Marfella R, et al. 1997. Metabolic and cardiovascular effects of carvedilol and atenolol in non-insulin-dependent diabetes mellitus and hypertension. A randomized, controlled trial. Ann Intern Med, 126:955-9.

Gosse P. 2005. Left ventricular hypertrophy as a predictor of cardiovascular risk. J Hypertens Suppl, 23:S27-S33.

Haenni A, Lithell H. 1994. Treatment with a beta-blocker with beta 2-agonism improves glucose and lipid metabolism in essential hypertension. Metabolism, 43:455-61

Hannedouche T, Landais P, Goldfarb B, et al. 1994. Randomised controlled trial of enalapril and beta blockers in non-diabetic chronic renal failure. BMJ, 309:833-7.

Henderson LS, Tenero DM, Baidoo CA, et al. 2006. Pharmacokinetic and pharmacodynamic comparison of controlled-release carvedilol and immediate-release carvedilol at steady state in patients with hypertension. Am J Cardiol, 98:17L-26L.
Jacob S, Rett K, Wicklmayr M, et al. 1996. Differential effect of chronic treatment with two beta-blocking agents on insulin sensitivity: the carvedilol-metoprolol study. J Hypertens, 14:489-94.

Kaplan N. 2005a. Systemic hypertension: mechanisms and diagnosis. In Zipes D, Libby P, Bonow R, et al. eds. Braunwald's Heart Disease. A Textbook of Cardiovascular Medicine. 7th ed. Philadelphia, Pensylvania: Elsevier Saunders. p 959-87.

Kaplan N. 2005b. Systemic Hypertension: Therapy. In Zipes D, Libby P, Bonow R, et al. eds. Braunwald's Heart Disease. A Textbook of Cardiovascular Medicine. 7th ed. Philadelphia, Pensylvania: Elsevier Saunders. p 989-1012.

Kasiske BL, Ma JZ, Kalil RS, et al. 1995. Effects of antihypertensive therapy on serum lipids. Ann Intern Med, 122:133-41.

Kramer BK, Ress KM, Erley CM, et al. 1992. Pharmacokinetic and blood pressure effects of carvedilol in patients with chronic renal failure. Eur J Clin Pharmacol, 43:85-8.

Lever AF, Harrap SB. 1992. Essential hypertension: a disorder of growth with origins in childhood? J Hypertens, 10:101-20.

Lindholm LH, Carlberg B, Samuelsson O. 2005. Should beta blockers remain first choice in the treatment of primary hypertension? A meta-analysis. Lancet, 366:1545-53.

Lithell H, Pollare T, Vessby B. 1992. Metabolic effects of pindolol and propranolol in a double-blind cross-over study in hypertensive patients. Blood Press, 1:92-101.

MacMahon S, Peto R, Cutler J, et al. 1990. Blood pressure, stroke, and coronary heart disease. Part 1, Prolonged differences in blood pressure: prospective observational studies corrected for the regression dilution bias. Lancet, 335:765-74.

MacMahon S, Rodgers A, Neal B, et al. 1997. Blood pressure lowering for the secondary prevention of myocardial infarction and stroke. Hypertension, 29:537-8.

Maitland-van der Zee AH, Klungel OH, Kloosterman JM, et al. 2001. The association between antihypertensive drug therapies and plasma lipid levels in the general population. J Hum Hypertens, 15:701-5.

Malminiemi K. 1995. Association between serum lipids, glucose tolerance, and insulin sensitivity during 12 months of celiprolol treatment. Cardiovasc Drugs Ther, 9:295-304.

Mani V, Van den Meiracker AH, Schalekamp MA. 1988. Do beta-blockers really increase peripheral vascular resistance? Review of the literature and new observations under basal conditions. Am J Hypertens, 1:91-6.

Mancia G, De BG, Dominiczak A, et al. 2007. 2007 Guidelines for the Management of Arterial Hypertension: The Task Force for the Management of Arterial Hypertension of the European Society of Hypertension (ESH) and of the European Society of Cardiology (ESC). J Hypertens, 25:1105-87.

Marchi F, Ciriello G. 1995. Efficacy of carvedilol in mild to moderate essential hypertension and effects on microalbuminuria: a multicenter, randomized, open-label, controlled study versus atenolol. Adv Ther, $12: 212-21$.

McTavish D, Campoli-Richards D, Sorkin EM. 1993. Carvedilol. A review of its pharmacodynamic and pharmacokinetic properties, and therapeutic efficacy. Drugs, 45:232-58.

Messerli FH, Aristizabal D, Soria F. 1993. Reduction of left ventricular hypertrophy: how beneficial? Am Heart J, 125:1520-4.

Messerli FH, Grossman E. 2004. beta-Blockers in hypertension: is carvedilol different? Am J Cardiol, 93:7B-12B.

Messerli FH, Grossman E, Goldbourt U. 1998. Are beta-blockers efficacious as first-line therapy for hypertension in the elderly? A systematic review. JAMA, 279:1903-7.

Morgan T. 1994. Clinical pharmacokinetics and pharmacodynamics of carvedilol. Clin Pharmacokinet, 26:335-46.

National Collaborating Centre for Chronic Conditions. 2006. Hypertension: management of hypertension in adults in primary care: partial update. London: Royal College of Physicians.

Neugebauer G, Gabor M, Reiff K. 1992. Disposition of carvedilol enantiomers in patients with liver cirrhosis: evidence for disappearance of stereoselective first-pass extraction. J Cardiovasc Pharmacol, 19 Suppl 1:S142-S6. 
Opie L, Yusuf S. 2005. Beta-blocking agents. In Opie LH, Gersh B eds. Drugs for the Heart. 6th ed. Philadelphia, Pensylvania: W.B. Saunders Company. p 1-32.

Osterberg L, Blaschke T. 2005. Adherence to medication. $N$ Engl J Med, 353:487-97.

Packer M. 2006. Controlled-release carvedilol: a concluding perspective. Am J Cardiol, 98:67L-9L.

Pollare T, Lithell H, Morlin C, et al. 1989a. Metabolic effects of diltiazem and atenolol: results from a randomized, double-blind study with parallel groups. J Hypertens, 7:551-9.

Pollare T, Lithell H, Selinus I, et al. 1989b. Sensitivity to insulin during treatment with atenolol and metoprolol: a randomised, double blind study of effects on carbohydrate and lipoprotein metabolism in hypertensive patients. BMJ, 298:1152-7.

Poole-Wilson PA, Swedberg K, Cleland JG, et al. 2003. Comparison of carvedilol and metoprolol on clinical outcomes in patients with chronic heart failure in the Carvedilol Or Metoprolol European Trial (COMET): randomised controlled trial. Lancet, 362:7-13.

Roberts WC. 1989. Recent studies on the effects of beta blockers on blood lipid levels. Am Heart J, 117:709-14.

Sarafidis PA, Bakris GL. 2006a. Antihypertensive therapy and the risk of new-onset diabetes. Diabetes Care, 29:1167-9.

Sarafidis PA, Bakris GL. 2006b. Antihypertensive treatment with betablockers and the spectrum of glycaemic control. QJM, 99:431-6.

Sarafidis PA, Bakris GL. 2006c. Are beta blockers passe for the treatment of hypertension? J Clin Hypertens (Greenwich), 8:239-40.

Sarafidis PA, Bakris GL. 2006d. Do the metabolic effects of beta blockers make them leading or supporting antihypertensive agents in the treatment of hypertension? J Clin Hypertens (Greenwich), 8:351-6.

Sarafidis PA, Bakris GL. 2006e. Microalbuminuria and chronic kidney disease as risk factors for cardiovascular disease. Nephrol Dial Transplant, 21:2366-74

Sarafidis PA, Bakris GL. 2008. State of hypertension management in the United States: confluence of risk factors and the prevalence of resistant hypertension. J Clin Hypertens (Greenwich). In press.

Sarafidis PA, Bakris GL. 2007. Metabolic effects of beta-blockers: importance of dissociating newer from conventional agents. J Hypertens, 25:249-52.
Sarafidis PA, Khosla N, Bakris GL. 2007. Antihypertensive therapy in the presence of proteinuria. Am J Kidney Dis, 49:12-26.

Sarafidis PA, Lasaridis A, Gousopoulos S, et al. 2004. Prevalence, awareness, treatment and control of hypertension in employees of factories of Northern Greece: the Naoussa study. J Hum Hypertens, 18:623-9.

Schulman SP, Weiss JL, Becker LC, et al. 1990. The effects of antihypertensive therapy on left ventricular mass in elderly patients. $N$ Engl $J$ Med, 322:1350-6.

Sica DA. 2007. beta-Blockers in Hypertension: A Reassessment of the Benefit of Combined alpha-/beta-Blockade. J Clin Hypertens (Greenwich), 9:4-9.

Stamler J, Stamler R, Neaton JD. 1993. Blood pressure, systolic and diastolic, and cardiovascular risks. US population data. Arch Intern Med, 153:598-615.

Tenero DM, Henderson LS, Baidoo CA, et al. 2006. Pharmacokinetic properties of a new controlled-release formulation of carvedilol. Am J Cardiol, 98:5L-16L.

US Renal Data System. 2005. USRDS 2005 Annual Data Report: Atlas of End-Stage Renal Disease in the United States. Bethesda, MD: National Institute of Diabetes and Digestive and Kidney Diseases.

Verdecchia P, Angeli F, Pittavini L, et al. 2004. Regression of left ventricular hypertrophy and cardiovascular risk changes in hypertensive patients. Ital Heart J, 5:505-10.

Weber MA, Bakris GL, Tarka EA, et al. 2006. Efficacy of a once-daily formulation of carvedilol for the treatment of hypertension. $J$ Clin Hypertens (Greenwich), 8:840-9.

Weiss R. 2006. Nebivolol: a novel beta-blocker with nitric oxide-induced vasodilatation. Vasc Health Risk Manag, 2:303-8.

Williams B, Poulter NR, Brown MJ, et al. 2004. Guidelines for management of hypertension: report of the fourth working party of the British Hypertension Society, 2004-BHS IV. J Hum Hypertens, 18:139-85.

Wolf-Maier K, Cooper RS, Kramer H, et al. 2004. Hypertension treatment and control in five European countries, Canada, and the United States. Hypertension, 43:10-17.

Yoshikawa T, Port JD, Asano K, et al. 1996. Cardiac adrenergic receptor effects of carvedilol. Eur Heart J, 17 Suppl B:8-16. 